\title{
PATRIMÔNIO CULTURAL E A PRESERVAÇÃO DO PASSADO PELO ESTADO: UM ESTUDO SOBRE O PROCESSO DE DESAPROPRIAÇÃO DO QUADRO “MISÉRIA E CARIDADE” DO PINTOR SERGIPANO HORÁCIO HORA
}

\section{CULTURAL PATRIMONY AND THE PRESERVATION OF THE PAST BY THE STATE: A STUDY ON THE DISAPPROPRIATION PROCESS OF THE PAINTING “MISÉRIA E CARIDADE” OF SERGIPE PAINTER HORÁCIO HORA}

HENRIQUE RIBEIRO CARDOSO

Doutor em Direito, Estado e Cidadania (UGF/Rio), com Pós-doutorado em Democracia e Direitos Humanos (IGC - Universidade de Coimbra) e Pós-doutorado em Direitos Humanos e Desenvolvimento (PPGCJ/UFPB); Mestre em Direito, Estado e Cidadania (UGF/Rio); Professor do Programa de Pós-graduação da Universidade Federal de Sergipe (PRODIR/UFS) e do Programa de Pós-graduação da Universidade Tiradentes (PPGD/UNIT); Promotor de Justiça Titular da Fazenda Pública em Sergipe (MPSE); Membro da Academia Sergipana de Letras Jurídicas (ASLJ). Líder do Grupo de Pesquisa Constitucionalismo, Cidadania e Concretização de Políticas Públicas (CNPq/UFS). henrique@mpse.mp.br

DANIELA CARVALHO ALMEIDA DA COSTA Doutora e Mestre em Direito Penal e Processo Penal pela Universidade de São Paulo - USP. Especialista em Direito Penal e Processual Penal pela Universidad de Salamanca. Professora Associada da Universidade Federal de Sergipe, vinculada ao Programa de Pós-graduação stricto sensu em Direito (PRODIR/UFS) e à graduação em direito. Líder do Grupo de Pesquisa Estudos sobre Violência e Criminalidade na Contemporaneidade (CNPq/UFS). dancacosta@hotmail.com 


\title{
LUCILLA MENEZES DA SILVA RAMOS
}

Mestre em Direito pelo Programa de Mestrado em Direito da Universidade Federal de Sergipe. Graduada em Direito e em História pela Universidade Federal de Sergipe. Advogada. lucillamenezes@gmail.com.

\section{RESUMO}

O trabalho analisa a preservação do patrimônio cultural brasileiro pelo Estado, através da intervenção estatal na propriedade privada por meio da desapropriação. Para tanto, valer-se-á do estudo de caso do processo judicial n‥ 201050100501, que tramita na justiça estadual de Sergipe. O objeto de estudo refere-se ao processo de desapropriação do quadro "Miséria e Caridade", datado de 1884, do pintor sergipano Horácio Hora. A metodologia escolhida foi o estudo de caso por possibilitar uma investigação empírica de um evento específico e revelador, permitindo entender a complexidade do fenômeno referente à proteção do patrimônio cultural. Assim, com a análise do referido processo judicial, pôde-se perceber 0 papel primordial desempenhado pelo instituto da desapropriação como um mecanismo hábil e apto a efetivar o comando constitucional referente à proteção dos bens culturais.

PALAVRAS-CHAVE: Patrimônio Cultural; Desapropriação de quadro; Estudo de Caso Concreto.

\begin{abstract}
The paper analyzes the preservation of the Brazilian cultural heritage by the state, through state intervention in private property through expropriation. For this, it will use the case study of the judicial process no. 201050100501, which is being processed in the state court of Sergipe. The object of study refers to the process of expropriation of the painting "Miséria e Caridade", dated from 1884, executed by the Sergipe painter Horácio Hora. The chosen methodology was the case study for enabling an empirical investigation of a specific and revealing event, allowing to understand the complexity of the phenomenon related to the protection of cultural heritage. Thus, with the analysis
\end{abstract}


of this judicial process, it was possible to perceive the primordial role played by the expropriation institute as a skillful mechanism and able to carry out the constitutional command concerning the protection of cultural goods.

KEYWORDS: Cultural Patrimony; Picture Expropriation; Case Law Study.

\section{INTRODUÇÃO}

A desapropriação é forma de intervenção do Estado na propriedade alheia, transferindo-a, compulsoriamente e de maneira originária, para o patrimônio estatal, fundamentando-se, para isso, no interesse público, após o devido processo legal.

O presente artigo parte do estudo de um caso concreto, bastante emblemático no cenário jurídico do Estado de Sergipe, especialmente no que se refere à proteção do patrimônio cultural por meio da expropriação. Trata-se do processo judicial de desapropriação, instaurado pelo Estado de Sergipe no ano de 2010, da obra "Miséria e Caridade", pintada pelo artista sergipano Horário Hora em 1884.

O objeto de estudo gerou o seguinte problema de pesquisa: em que medida a desapropriação contribui para a salvaguarda do patrimônio cultural brasileiro, dentro do comando constitucional relativo à cultura e aos bens culturais?

Entendeu-se ser o estudo de caso a metodologia mais adequada para explorar o problema proposto, pois possibilita a investigação empírica de um caso específico e revelador, permitindo entender a complexidade do fenômeno, bem ainda sua possível extensão a situações assemelhadas. Neste sentido, a estratégia de pesquisa utilizada é especialmente importante já que a decisão judicial estudada é considerada precursora, pois foi a única a determinar a desapropriação de um bem móvel, que já havia sido tombado, no Estado de Sergipe, com o objetivo de protegêlo diante do seu inestimável valor cultural.

Com o olhar voltado para o caso, ou seja, para o processo judicial de desapropriação do quadro "Miséria e Caridade", o presente artigo tem por objetivo investigar como a desapropriação pode ser utilizada para salvaguardar o patrimônio cultural, estabelecendo-se, para tanto, conexões com a própria noção de patrimônio 
cultural consolidada na Constituição Federal de 1988 e com os aspectos teóricos da intervenção do Estado na propriedade.

O quadro, originalmente, foi doado para o Hospital Amparo de Maria, localizado na cidade de Estância/SE, pelo próprio Horácio Hora e lá permaneceu até o ano de 2006, quando foi penhorado pela Justiça do Trabalho em Sergipe, para quitar dívidas trabalhistas desse nosocômio.

Diante da situação precária que se encontrava a obra e da possibilidade de o quadro sair do Estado de Sergipe ou até mesmo do Brasil, caso fosse a hasta pública, foi interposta ação de desapropriação ajuizada pelo Estado de Sergipe em face do Hospital Amparo de Maria no ano de 2010.

Assim sendo, no ano de 2010, o Estado de Sergipe, por meio de sua Procuradoria do Estado, interpôs uma Ação de Desapropriação com Imissão Provisória na Posse contra o Hospital Amparo de Maria, a fim de desapropriar o quadro "Miséria e Caridade".

Aludido feito é público e tramita de forma virtual na justiça estadual comum de Sergipe com o número originário 201050100501, podendo ser acessado por advogados cadastrados no sistema do Tribunal de Justiça de Sergipe e por servidores dessa instituição.

O estudo de caso aqui desenvolvido foi realizado a partir de duas técnicas: revisão bibliográfica e pesquisa documental, sendo o processo judicial, em si, considerado um documento.

A estruturação do artigo se deu pelo raciocínio indutivo, em que se partirá do estudo de caso, para depois aprofundar o debate acerca da noção de patrimônio cultural dentro da Constituição Federal de 1988, explicitando como o Estado pode intervir na propriedade privada, especialmente por meio da desapropriação. Como este foi o instituto utilizado pelo Estado de Sergipe para fins de proteção da obra de arte em questão, a presente análise não enveredará pelo estudo das demais formas de intervenção na propriedade.

Para fins de delimitação do campo de pesquisa, uma vez que o processo judicial de desapropriação encontra-se atualmente em sede de recurso, o estudo se deterá em nível de primeiro grau, ou seja, da inicial até a prolação da sentença. $A$ análise dos fatos, e do processo que o abarca, não adentrará no mérito da lide, ou 
seja, na discussão quanto ao específico valor ou modo de pagamento da indenização, vez que excede o objetivo proposto.

\section{O PROCESSO DE DESAPROPRIAÇÃO DO QUADRO “MISÉRIA E CARIDADE”. A CULTURA COMO UM DIREITO FUNDAMENTAL}

Em 09 de julho de 2010 foi distribuída na $2^{\text {a }}$ Vara da Comarca de Estância/SE uma Ação de Desapropriação com Imissão Provisória na Posse ajuizada pelo Estado de Sergipe. A inicial narra a crise financeira pela qual passa o Hospital Amparo de Maria, onde vários bens foram penhorados para quitar dívidas trabalhistas do nosocômio.

Um destes bens que se encontravam penhorados era o quadro "Miséria e Caridade" do pintor sergipano Horácio Hora. Aludida obra foi pintada no ano de 1884 e é categorizada em publicações técnicas como obra representante do Romantismo brasileiro.

Importante destacar que a tela fora tombada pelo Estado de Sergipe mediante o Decreto no. 23.204 de 03/05/2000: a obra artística que foi desapropriada já era acautelada por umas das formas de intervenção do Estado na propriedade, intervenção essa que não retira a propriedade do bem ${ }^{1}$, ao contrário da desapropriação.

Como o quadro estava penhorado pela justiça trabalhista de Sergipe e também se encontrava em precárias condições, o juízo trabalhista determinou que referido bem ficasse custodiado pelo Estado de Sergipe já no ano de 2006 (G1, 2017), a fim de preservá-lo e garantir a sua perpetuação para o gozo das presentes e futuras gerações.

Diante de tal fato, e provocado por tal medida, entendeu o Estado de Sergipe que a desapropriação seria a melhor forma de preservar esse relevante patrimônio artístico sergipano.

\footnotetext{
10 tombamento, previsto no texto constitucional no art. 216, é uma das formas de intervenção administrativa na propriedade, pela qual o Poder Público sujeita determinados bens à sua perene conservação para preservação dos valores culturais neles presentes. (MELLO, 2012, p. 926).
} 
No estudo de caso analisado, percebeu-se que o Estado seguiu a normativa legal e editou o Decreto $\mathrm{n}^{0}$. 26.842, de 20/01/2010, definindo a preservação do quadro "Miséria e Caridade", de 1884, do pintor sergipano Horácio Hora, como de utilidade pública para fins de desapropriação. A obra de arte foi avaliada pela Secretaria de Estado da Cultura de Sergipe no ano de 2010 por $\mathrm{R} \$ 20.000,00$ (vinte mil reais).

$\mathrm{Na}$ inicial da ação judicial analisada, o Estado justifica o porquê da desapropriação da obra artística em questão, utilizando de estudos jurídicos acerca do tema desapropriação, além da apresentação da situação fática que impôs essa atuação ablativa do Estado.

Percebe-se que o Estado de Sergipe valeu-se de sua competência para promover a desapropriação da obra "Miséria e Caridade" a fim de salvaguardar o patrimônio cultural que se encontrava ameaçado. Para isso, interpôs a ação judicial cabível com um pedido de urgência para ser imitido na posse do bem antes do julgamento de mérito da ação.

Ainda no ano de 2010, em 16/07/2010, o juízo analisou o pedido de urgência formulado pelo Estado e deferiu a imissão provisória na posse, com fundamento nos artigos 13 e 15 do Decreto-Lei oㅜ 3.365/1941².

Nesse despacho foi nomeado um perito, artista plástico sergipano, para proceder à avaliação do bem e estimar seus honorários, abrindo-se às partes o prazo

\footnotetext{
2 Dispõe sobre desapropriações por utilidade pública. "Art. 13. A petição inicial, além dos requisitos previstos no Código de Processo Civil, conterá a oferta do preço e será instruída com um exemplar do contrato, ou do jornal oficial que houver publicado o decreto de desapropriação, ou cópia autenticada dos mesmos, e a planta ou descrição dos bens e suas confrontações. Parágrafo único. Sendo o valor da causa igual ou inferior a dois contos de réis (2:000\$0), dispensam-se os autos suplementares. Art. 14. Ao despachar a inicial, o juiz designará um perito de sua livre escolha, sempre que possível, técnico, para proceder à avaliação dos bens. Parágrafo único. O autor e o réu poderão indicar assistente técnico do perito. Art. 15. Se o expropriante alegar urgência e depositar quantia arbitrada de conformidade com o art. 685 do Código de Processo Civil, o juiz mandará imiti-lo provisoriamente na posse dos bens; § 1ำ A imissão provisória poderá ser feita, independente da citação do réu, mediante o depósito: a) do preço oferecido, se este for superior a 20 (vinte) vezes o valor locativo, caso o imóvel esteja sujeito ao imposto predial; b) da quantia correspondente a 20 (vinte) vezes o valor locativo, estando o imóvel sujeito ao impôsto predial e sendo menor o preço oferecido; c) do valor cadastral do imóvel, para fins de lançamento do imposto territorial, urbano ou rural, caso o referido valor tenha sido atualizado no ano fiscal imediatamente anterior; d) não tendo havido a atualização a que se refere o inciso c, o juiz fixará independente de avaliação, a importância do depósito, tendo em vista a época em que houver sido fixado originalmente o valor cadastral e a valorização ou desvalorização posterior do imóvel. $\S 2^{\circ} \mathrm{A}$ alegação de urgência, que não poderá ser renovada, obrigará o expropriante a requerer a imissão provisória dentro do prazo improrrogável de 120 (cento e vinte) dias. § 3 Excedido o prazo fixado no parágrafo anterior não será concedida a imissão provisória. § 4ํㅡ $\mathrm{A}$ imissão provisória na posse será registrada no registro de imóveis competente". (BRASIL, 1941).
} 
de 05 (cinco) dias para indicação de assistentes técnicos e apresentação de quesitos. O perito em questão arbitrou os honorários periciais em $20 \%$ em cima do valor do bem a ser avaliado.

Ocorre que o Estado de Sergipe pronunciou-se nos autos requerendo a destituição do perito indicado judicialmente, por entender que o mesmo não apresentou prova de especialidade na perícia que seria realizada, além do que não seria razoável arbitrar o valor dos honorários em $20 \%$ do valor da obra periciada.

Nesse mesmo sentido, pleiteou o Estado que a Universidade de Sergipe ou outra entidade que possuísse profissionais reconhecidamente gabaritados em artes fossem oficiadas, a fim de ceder nomes a realizarem a perícia em comento.

Em 20 de julho de 2010 foi proferida decisão deferindo a imissão provisória da posse pelo Estado, ficando o quadro nas dependências da Secretaria de Estado da Cultura aos cuidados de profissionais gabaritados.

Destaca-se que o Estado, antes mesmo da realização de uma perícia oficial, guiou-se pela avaliação promovida pela Secretaria de Estado da Cultura e depositou em juízo o valor de $\mathrm{R} \$ 20.000,00$.

Realizada a perícia oficial apenas em 2016, foi apresentado laudo de avaliação da obra no valor de $\mathrm{R} \$ 500.000,00$ (quinhentos mil reais), valor esse não impugnado pelo Estado de Sergipe, requerendo apenas a implementação do pagamento pelo regime de precatórios. E é justamente nesse ponto que reside a discussão que corre até hoje na justiça, pois, o nosocômio insiste em que o pagamento da indenização deve ser, além de justa e prévia, em dinheiro, ao passo que Estado entende que o pagamento pode ser feito pelo regime de precatórios.

O julgamento da lide em primeiro grau ocorreu na data de 12 de fevereiro de 2017 e o juízo entendeu como procedente o pedido proposto pelo Estado de Sergipe para decretar a desapropriação do quadro artístico "Miséria e Caridade", do pintor Horácio Hora. Na ocasião, também homologou o valor indicado em laudo pericial (quinhentos mil reais) e, quanto à diferença da indenização, entendeu que o valor deveria ser adimplido mediante o regime de precatórios, observando-se a ordem legal.

O Hospital Amparo de Maria recorreu da decisão e o processo ainda se encontra em andamento, pendente de julgamento em segundo grau, discutindo-se a questão da forma de pagamento da indenização. A controvérsia, em síntese, refere- 
se ao rito a ser observado para o pagamento da diferença entre o valor previamente depositado pelo expropriante, Estado de Sergipe $(\mathrm{R} \$ 20.000,00)$, e o fixado no laudo pericial $(\mathrm{R} \$ 500.000,00)$.

Quanto a essa controvérsia, o Supremo Tribunal Federal (STF) analisará no Recurso Extraordinário (RE) 922144 (Tema 865) (BRASIL, 2015), se a indenização prévia e em dinheiro para desapropriação por necessidade ou utilidade pública, prevista no artigo 5ํㅜㄹ inciso XXIV, da Constituição Federal, se compatibiliza com o regime de precatórios, instituído pelo artigo 100 da CF/88. O tema foi, por unanimidade, acatado como de repercussão geral pelo Plenário Virtual do Supremo em 16 de novembro de 2015.

O referido recurso extraordinário faz alusão à forma de adimplemento da diferença entre o valor inicialmente depositado pelo ente expropriante e o definitivamente assentado pela Corte de Justiça de origem. Contudo, como não foi determinado o sobrestamento dos processos com fundamento em idêntica controvérsia até o pronunciamento definitivo da Suprema Corte, decidiu o juízo de origem, no caso específico da desapropriação da pintura de Horácio Hora, que a diferença da indenização deverá ser adimplida mediante o regime de precatórios, observando-se a ordem legal.

Com isso, a obra "Miséria e Caridade" é, na atualidade, é um dos quadros mais valiosos de todos os pintores sergipanos, atingindo o valor estimado de $R \$$ 1.200.000,00 (um milhão e duzentos mil reais) no ano de 2017, podendo alcançar, quando for realizado o pagamento, o valor de $R \$ 4.000 .000,00$ (quatro milhões de reais) (G1, 2017).

Como se pode perceber a partir da narrativa fática do processo judicial, a intenção de preservação de bem móvel com valor histórico foi justamente o fundamento do judicial apresentado, sendo a desapropriação por utilidade pública o mecanismo utilizado pelo Estado de Sergipe para fazer cumprir o prescritivo constitucional referente a preservação das fontes da cultura nacional.

Valeu-se o Estado de Sergipe de um mecanismo de proteção conferido pelo ordenamento jurídico pátrio, vez que defender a identidade nacional ou local é fator motivador da tutela do patrimônio cultural, a fim de que possa ocorrer a identificação 
de gerações futuras com o contexto social a que estão inseridos, tendo, nesse caso, o Estado um papel primordial.

Além desse motivador social que atua como base fundamental para a construção de uma ideia em que a cultura se apresenta como essencial para a formação humana, tem-se o papel desempenhado pelo instituto da desapropriação como um mecanismo apto a tutelar o patrimônio cultural nacional.

Acrescente-se, ainda, como será explicitado nos próximos tópicos, ser dever do Estado valorizar a cultura e garantir seu exercício e a difusão das manifestações culturais, bem como assegurar o acesso às fontes de cultura nacional. Esse dever advém dos princípios fundamentais do Estado Democrático de Direito, "que incluem a cidadania, a dignidade da pessoa humana, a construção de uma sociedade livre, justa e solidária, a garantia do desenvolvimento nacional, a erradicação da pobreza e da marginalização, a redução da desigualdade sociais e regionais e a promoção do bem de todos" (SALLES, 2014, p. 26-27).

Os direitos culturais recebem a qualificação de direitos fundamentais, mesmo não estando elencados conjuntamente com os demais direitos fundamentais previstos na Constituição Federal de 1988. Neste sentido, diversos estudiosos da temática reafirmam essa compreensão, esclarecendo que os direitos culturais são "direitos constitucionais atuais e fundamentais" (SILVA, 2001, p. 50; CUNHA FILHO, 2000, p. 43).

Portanto, os direitos fundamentais culturais, em uma interpretação stricto sensu, não devem ser entendidos de forma diferente dos demais, gozando de semelhante proteção à conferida aos direitos econômicos, sociais, e individuais, dentre outros. Além disso, em uma interpretação lato sensu, os direitos fundamentais podem ser compreendidos como a expressão da cultura humana em um Estado constitucional (CUNHA FILHO, 2004, p. 36-37).

Pode-se considerar que existe uma multiplicidade de terminologias que se referem ao âmbito dos direitos fundamentais. Na visão de Paulo Bonavides (2010, p. 562), o direito é considerado fundamental quando ele é essencial para a garantia de uma vida digna e para o exercício da cidadania, os quais estariam vinculados essencialmente aos princípios da liberdade e dignidade da pessoa humana. 
Nesta linha, os direitos fundamentais são aqueles que estão expostos de forma expressa na Constituição (formalmente constitucionais, previstos no Título II da $\mathrm{CF} / 88$ ); aqueles de maior relevância dentro do ordenamento jurídico constitucional, tendo em vista seu caráter essencial na proteção da dignidade da pessoa humana, da cidadania e da liberdade (direitos fundamentais dispersos na $\mathrm{CF} / 88$ ); e aqueles que, apesar de sua elevada importância, não estão previstos expressamente na Constituição (direitos fundamentais sem assento constitucional).

Do mesmo modo, salienta-se que os direitos fundamentais devem estar em consonância com os preceitos estabelecidos pelo sistema internacional de direito humanos. Aqui, converge-se na ideia de que os direitos fundamentais não se confundem com os direitos humanos, apesar de serem interdependentes e interrelacionados no que toca a efetivação e concretização desses direitos, com o objetivo último de assegurar os direitos fundamentais sociais, econômicos e culturais (VARELLA, 2013, p. 61-62).

No entendimento de Francisco Humberto Cunha Filho (2000, p. 41), para que os direitos culturais se caracterizem como direitos fundamentais, para que recebam essa adjetivação, faz-se necessário verificar os seguintes perfis:

1) Devem estar inseridos no texto constitucional, preferencialmente no capítulo dos direitos e garantias fundamentais; 2) se não estiverem na Constituição, a sua existência deve ser tão significativa ao ponto de ser abraçada pelos princípios que informam o conjunto de direitos fundamentais, em seu aspecto material, dos quais sobressai-se o que sintetiza e justifica os demais, a multimencionada dignidade da pessoa humana. (CUNHA FILHO, 2000, p. 41).

O mesmo autor afirma que caso estejam inseridos em um desses perfis, gozarão de tratamento jurídico diferenciado:

1) Proteção especial quanto à supressão do ordenamento; 2) a aplicabilidade imediata do ponto de vista de eficácia jurídica, bem como proteção contra a doutrina que advoga a existência de normas fundamentais programáticas, na seara dos direitos fundamentais; doutrina esta que, ao meu ver, usa tal argumentação como subterfúgio para não efetivar ou no mínimo procrastinar a prestação determinada pela Lei Maior. (CUNHA FILHO, 2000, p. 41-42). 
Portanto, o mero afastamento tópico entre os artigos tratados como direitos fundamentais (art. 5, CF/88) e os artigos que tratam dos direitos culturais (art. 215 a 216-A, CF/88) não é suficiente para compreendê-los como não fundamentais. Notase que alguns dos incisos presentes no art. $5^{\circ}$ da CF/88 tratam da temática dos direitos culturais, tais como os incisos IX (liberdade de expressão artística), XXVII e XXVIII (direitos autorais e conexos) e LXXIII (direito à proteção do patrimônio cultural).

Neste sentido, da essencialidade da proteção cultural, insere-se a desapropriação por utilidade pública como um dos mecanismos dispostos pelo Estado brasileiro para a preservação e a conservação adequada de arquivos, documentos e outros bens de valor histórico ou artístico.

Com o estudo de caso aqui proposto, pode-se visualizar que a tutela do patrimônio cultural brasileiro, como dispõe o caput do art. 215, é garantida pelo Estado, sendo a desapropriação um dos meios aptos a salvaguardar o patrimônio cultural brasileiro, mesmo que para isso haja a restrição ao direito de propriedade individual.

Percebe-se, deste modo, a centralidade e a atualidade do tema proposto e discutido, em que a proteção do patrimônio cultural conferida pela Constituição de 1988 apresenta-se como uma garantia para que a coletividade tenha a oportunidade de conhecer sua própria história e a história dos diferentes grupos formadores da sociedade.

\section{PATRIMÔNIO CULTURAL NA CONSTITUIÇÃO DE 1988 E A IMPORTÂNCIA DE SUA TUTELA}

No ordenamento jurídico brasileiro, o direito à cultura tem previsão constitucional, estando inserido no caput do art. 215 da CF/88, que prevê o seguinte: "O Estado garantirá a todos o pleno exercício dos direitos culturais e acesso às fontes da cultura nacional, e apoiará e incentivará a valorização e a difusão das manifestações culturais".

A Constituição Federal de 1988 conferiu ao patrimônio cultural proteção legal abrangente de bens de natureza material e imaterial, tomados individualmente ou em 
conjunto, portadores de referência à identidade, à ação e à memória dos diferentes grupos formadores da sociedade brasileira.

Extrai-se dessa previsão a ampla cobertura, na esfera constitucional, da tutela ao patrimônio cultural em sua acepção mais abrangente, consagrando o constituinte a expressão patrimônio cultural como sendo aquela que se contrapõe ao patrimônio natural, sendo este formado ao largo de qualquer interferência humana.

Dentro ainda da seara constitucional, tem-se que a CF/88 em seu art. 24, VII, é expressa ao estabelecer a competência concorrente da União, dos Estadosmembros, do Distrito Federal e dos Municípios para legislarem sobre o patrimônio cultural (SILVA, 2001, p. 43-44).

Com relação ao direito à cultura, tem-se que 0 art. 215 da CF/88 garante a todos o exercício desse direito e 0 acesso às fontes da cultura nacional, comprometendo-se o Estado, como percebe Ranieri (2008, p. 312), a apoiar e incentivar a valorização e a difusão das manifestações culturais 3 :

\begin{abstract}
Art. 215. O Estado garantirá a todos o pleno exercício dos direitos culturais e acesso às fontes da cultura nacional, e apoiará e incentivará a valorização e a difusão das manifestações culturais. $\S 1^{\circ} \bigcirc$ Estado protegerá as manifestações das culturas populares, indígenas e afro-brasileiras, e das de outros grupos participantes do processo civilizatório nacional; $\S 2^{\circ} \mathrm{A}$ lei disporá sobre a fixação de datas comemorativas de alta significação para os diferentes segmentos étnicos nacionais; $\S 3^{\circ}$ A lei estabelecerá o Plano Nacional de Cultura, de duração plurianual, visando ao desenvolvimento cultural do País e à integração das ações do poder público que conduzem à: (Incluído pela Emenda Constitucional no 48, de 2005); I - defesa e valorização do patrimônio cultural brasileiro; (Incluído pela Emenda Constitucional ํo 48, de 2005); II - produção, promoção e difusão de bens culturais; (Incluído pela Emenda Constitucional no 48, de 2005); III - formação de pessoal qualificado para a gestão da cultura em suas múltiplas dimensões; (Incluído pela Emenda Constitucional $n^{\circ}$ 48, de 2005); IV - democratização do acesso aos bens de cultura; (Incluído pela Emenda Constitucional oㅜ 48, de 2005); V - valorização da diversidade étnica e regional. (Incluído pela Emenda Constitucional no 48 , de 2005) (BRASIL, 1988, s.p.).
\end{abstract}

Da leitura do dispositivo, percebe-se que o constituinte se mostrou preocupado em garantir a todos os cidadãos brasileiros o efetivo exercício dos direitos culturais, o acesso às fontes da cultura nacional e a liberdade das manifestações

\footnotetext{
${ }^{3}$ Faz-se necessário transcrever os artigos 215 e 216 da Constituição Federal de 1988 por serem fundamentais para o desenvolvimento da argumentação que se segue.
} 
culturais (CAMPELLO; COSTA, 2017, p. 153). Para tanto, determina ao Estado que garanta a todos o exercício dos direitos culturais e estabelece as competências estatais a serem cumpridas na realização dessa função.

Segundo Zandonade (2012, p. 75), a Constituição de 1988 adotou o modelo da "democracia cultural, cuja dimensão jurídica se fundamenta nos princípios da isonomia e da liberdade de expressão, do planejamento e da participação popular".

De forma direta, o art. 216 da CF/88 define o objeto de patrimônio cultural a ser tutelado pelo ordenamento jurídico brasileiro, estabelecendo como parâmetro de seleção a representatividade do bem para a memória, a identidade e a ação dos diversos grupos formadores da sociedade brasileira (DANTAS, 2013, p. 233). referido artigo destaca:

\begin{abstract}
Art. 216. Constituem patrimônio cultural brasileiro os bens de natureza material e imaterial, tomados individualmente ou em conjunto, portadores de referência à identidade, à ação, à memória dos diferentes grupos formadores da sociedade brasileira, nos quais se incluem: I - as formas de expressão; II - os modos de criar, fazer e viver; III - as criações científicas, artísticas e tecnológicas; IV - as obras, objetos, documentos, edificações e demais espaços destinados às manifestações artístico-culturais; $V$ - os conjuntos urbanos e sítios de valor histórico, paisagístico, artístico, arqueológico, paleontológico, ecológico e científico. $\S 1^{\circ}$ O Poder Público, com a colaboração da comunidade, promoverá e protegerá o patrimônio cultural brasileiro, por meio de inventários, registros, vigilância, tombamento e desapropriação, e de outras formas de acautelamento e preservação; § $2^{\circ}$ Cabem à administração pública, na forma da lei, a gestão da documentação governamental e as providências para franquear sua consulta a quantos dela necessitem; § 3 A lei estabelecerá incentivos para a produção e 0 conhecimento de bens e valores culturais; $\S 4$ 은 Os danos e ameaças ao patrimônio cultural serão punidos, na forma da lei; § $5^{\circ}$ Ficam tombados todos os documentos e os sítios detentores de reminiscências históricas dos antigos quilombos; $\S 6$ ㅌ É facultado aos Estados e ao Distrito Federal vincular a fundo estadual de fomento à cultura até cinco décimos por cento de sua receita tributária líquida, para o financiamento de programas e projetos culturais, vedada a aplicação desses recursos no pagamento de: (Incluído pela Emenda Constitucional no 42, de 19.12.2003). I - despesas com pessoal e encargos sociais; (Incluído pela Emenda Constitucional ํo 42, de 19.12.2003); II - serviço da dívida; (Incluído pela Emenda Constitucional no 42, de 19.12.2003); III - qualquer outra despesa corrente não vinculada diretamente aos investimentos ou ações apoiados. (Incluído pela Emenda Constitucional no 42, de 19.12.2003) (BRASIL, 1988, s.p).
\end{abstract}

Assim, no que se refere à atuação dos entes federais no tratamento da cultura, a CF/88, além de afirmar que é dever comum de todos os entes políticos da federação proporcionar meios de acesso à cultura (art. 23, inciso V), também buscou assegurar 
competência concorrente para legislar sobre cultura (art. 24, inciso IX), limitando-se a União a estabelecer normas gerais, e competindo aos Estados legislar de forma suplementar.

Na técnica legislativa adotada, quando a União não exercer sua competência, os Estados poderão legislar de forma plena para atender a suas peculiaridades; tais disposições constitucionais permitiram que vários Estados da Federação criassem legislações de incentivo e fomento à cultura (SILVA, 2001, p. 44).

Dessa forma, a cultura na CF/88 teve grande destaque, sendo-lhe, inclusive, concedida uma seção própria no texto constitucional. Além dessa importante seção, que menciona os arts. 215 e 216, a Constituição de 1988, como já referido, é permeada de artigos que refletem o dever estatal em garantir o acesso pleno à cultura, valorizando a cultura nacional e as matrizes étnicas formadoras da sociedade brasileira, além da preservação do patrimônio cultural.

Ressalta Zandonade (2012, p. 64) que a nomenclatura "patrimônio cultural brasileiro", inserida de forma inédita na CF/88, traduz justamente a ampla concepção de cultura de matiz antropológica e sociológica, indo além do saber formal e acadêmico ${ }^{4}$, conforme se apreende da análise feita pela autora dos trabalhos desenvolvidos pela Comissão da Família, da Educação, da Cultura e Esportes, da Ciência e Tecnologia e da Comunicação na Assembleia Nacional Constituinte.

Sobre esse ponto, destaca Zandonade que, ao invés da estreita noção que inspirava a legislação anterior, calcada na proteção de objetos filiados a padrões de conhecimento formais, a Assembleia Nacional Constituinte teria adotado uma concepção ampla de cultura, perceptível na determinação da tutela dos traços característicos do modo de vida da sociedade brasileira, em variadas facetas de grupos participantes de sua formação.(ZANDONADE, 2012, p. 52).

$\mathrm{Na}$ redefinição promovida pela CF/88, estão protegidas as formas de expressão; os modos de criar, fazer e viver; as criações científicas, artísticas e

\footnotetext{
${ }^{4}$ A concepção de patrimônio presente no Decreto-Lei no 25/1937 advém justamente da ideia de excepcionalidade do bem a ser salvaguardado. No contexto em que foi promulgado o referido decreto, Zandonade (2012, p. 50) aponta que somente os bens de caráter notável mereceriam proteção. Para Funari e Pelegrini (2006): "Somente na década de 1980 foi consolidada entre os especialistas uma acepção ampliada do conceito de patrimônio, compreendido não só por produções de artistas ou intelectuais reconhecidos, mas estendido às criações anônimas, oriundas da alma popular" (FUNARI; PELEGRINI, 2006, p. 36).
} 
tecnológicas; as obras, os objetos, os documentos, as edificações e os demais espaços destinados às manifestações artístico-culturais; os conjuntos urbanos e sítios de valor histórico, paisagístico, artístico, arqueológico, paleontológico, ecológico e científico. Este conjunto representa o patrimônio cultural brasileiro.

Essa preocupação com a salvaguarda do patrimônio cultural não esteve presente apenas na atual Constituição, mas também nas discussões dos intelectuais que participaram dos movimentos modernistas de 1922, sendo intensificada na década de 1930 através de políticas públicas (DANTAS, 2013, p. 225).

Conforme destacam Nascimento e Passos (2012), o movimento artístico modernista brasileiro, que organizara a Semana de Arte Moderna de 1922, mostrara a preocupação com as discussões sobre a natureza da identidade nacional. Apontam que, cem anos após a emancipação política brasileira, deveria a sociedade como um todo promover a independência cultural da nação, sendo necessário, para tanto, que se redescobrissem e se revalorizassem os elementos considerados típicos.

Contudo, somente no final da década de 30 do século passado, mais precisamente no Estado Novo, foi efetivada uma política nacional de preservação do patrimônio cultural brasileiro com uma produção legislativa para esse fim.

Nesse sentido é editado o Decreto-Lei n $25 / 1937^{5}$, e, por meio deste diploma legal, criou-se o tombamento como instituto jurídico de regulação governamental, determinando o que poderia receber status de patrimônio cultural nacional e ser objeto de acautelamento oficial.

Surge, assim, o SPHAN ${ }^{6}$ - Serviço do Patrimônio Histórico e Artístico Nacional -, que em seus primeiros anos, conforme destaca Dantas (2013, p. 226) teve a difícil tarefa de determinar os alicerces culturais da nacionalidade. O objetivo do SPHAN foi moldar a face do país, conferindo-Ihe visibilidade internacional através do estudo de tradições cuja imanência temporal e espacial fosse devidamente estabelecida (VELOSO, 1996, p. 78).

No final da década de 80 do século passado, os meios estatais adotados para fins de tutela do patrimônio cultural brasileiro são expressos na CF/88 e na legislação

\footnotetext{
${ }^{5}$ Com relação ao Decreto-Lei no. 25/37, Fiorillo e Ferreira (2017, p. 163) aduzem que foi esse diploma legal que lançou os primeiros conceitos jurídicos de patrimônio cultural, sendo referidos conceitos ampliados quando da promulgação da $\mathrm{CF} / 88$.

${ }^{6}$ Art. 4을 do Decreto-Lei № 25 de 1937. (BRASIL, 1937)
} 
ordinária. Em diversos artigos da Constituição atual, pode-se observar a delimitação de um regime voltado à proteção do patrimônio cultural, restando evidenciada a preocupação do legislador constituinte em garantir a salvaguarda desse bem jurídico social.

O art. 23, III, da CF/88 preceitua que ser competência comum da União, dos Estados, do Distrito Federal e dos Municípios proteger os documentos, as obras e outros bens de valor histórico, artístico e cultural, os monumentos, as paisagens naturais notáveis e os sítios arqueológicos (SILVA, 2001, p. 43).

Dessa forma, a Constituição de 1988 firma o entendimento de que todos os entes políticos são competentes e responsáveis pela manutenção e proteção dos bens jurídicos de valor cultural. Logo, as ações governamentais - tanto administrativas como políticas - de cada ente público deverão almejar a implementação de atos de preservação e de valorização da cultura, sendo a desapropriação também utilizada para salvaguardar o patrimônio cultural, como delineado no estudo de caso envolvendo a pintura "Miséria e Caridade".

\section{A INTERVENÇÃO DO ESTADO NA PROPRIEDADE COMO FROMA DE GARANTIR A PROTEÇÃO AO PATRIMÔNIO CULTURAL}

O Brasil assegura constitucionalmente o direito de propriedade, não o considerando, entretanto, um direito absoluto, sendo possível a intervenção estatal nesse campo. Referida intervenção tem como balizas, de um lado, a legalidade e a vedação ao enriquecimento ilícito do Estado, e de outro, a atribuição de função social à propriedade e a supremacia do interesse público, reconhecendo-se que o direito do proprietário de determinado bem pode ser mitigado para atender aos interesses da coletividade.

Com relação ao direito de propriedade - direito de utilizar, fruir livremente, dispor como bem the aprouver e reaver de quem quer que detenha o bem indevidamente - este é assegurado expressamente na Constituição Federal de 1988, sobretudo no artigo 5ำ, XXII: "é garantido o direito de propriedade." O artigo 1.228 do Código Civil brasileiro define propriedade como sendo o exercício das faculdades de 
uso, gozo, disposição e reivindicação da coisa. Acerca deste conceito, a percepção que se tem é de que "a propriedade no Código Civil não corresponde à projeção da propriedade no sistema de direito civil. Por sua vez, o conceito civilístico de propriedade já não corresponde àquilo que pretende o projeto constitucional." (FARIAS; ROSENVALD, 2011, p. 201).

Harada (2015) explicita que as faculdades de usar, gozar e dispor são provenientes do direito romano e correspondem, respectivamente, em jus utendi, fruendi et abutendi. Implicam na possibilidade de o proprietário usar a coisa como bem Ihe aprouver, o que, por decorrência, afasta o exercício da mesma faculdade por terceiros. Ademais, o aforismo em latim refere-se, da mesma forma, à faculdade de colher os frutos da coisa, sejam elas civis ou naturais. Por fim, relaciona as faculdades ao abusus do direito romano, "abuso este que se resume em dispor, alienar ou consumir a coisa". (HARADA, 2015, p. 2).

Dando um passo além, Fiúza aduz que no universo do direito das coisas, a propriedade poderia ser definida como a situação jurídica consistente em uma relação dinâmica e complexa entre uma pessoa, o dono, e a coletividade, em virtude da qual são assegurados àquele os direitos exclusivos de usar, fruir, dispor e reivindicar, respeitados, porém, os direitos da coletividade. Aponta, ainda, criticamente, que "dizer que propriedade ou domínio é direito de usar, fruir, dispor e reivindicar é prender-se à definição analítica do Direito Romano" (FIÚZA, 2010, p. 768).

Numa compreensão mais atual, a propriedade é uma relação jurídica que vincula o direito do proprietário à função social do bem, o que, consequentemente, introduz a coletividade como parte dessa relação.

Essa socialização do direito à propriedade, também percebida por Moura (2014, p.72), traz uma concepção de que possíveis restrições ao uso e gozo não seriam apenas limitações, mas um novo entendimento do próprio sentido dessa propriedade inserida em políticas públicas de bem-estar coletivo.

$\mathrm{Na}$ contemporaneidade, o exercício da propriedade privada caminha em consonância com as disposições de ordem pública vigente, de forma que se confira a proteção da liberdade individual desde que observados os interesses coletivos, conforme esclarecem Fiorillo e Ferreira na seguinte passagem: 


\begin{abstract}
Sucessivamente, o regime dos bens culturais foi explicado em termos mais precisos, abandonando a teoria das limitações ao direito de propriedade, não apropriada para justificar todos os efeitos ligados àquela qualificação e especialmente aos poderes atribuídos à Administração Pública sobre tais bens. Constatou-se que estes teriam assumido a configuração de bens de interesse público sobre os quais a Administração pretendia possuir verdadeiros e próprios poderes in rem. Estaríamos tratando, como explica parte da doutrina italiana, de bens privados que assumiriam a finalidade de "público interesse", sendo certo que deveriam sujeitar-se a um particular regime no que diz respeito à disponibilidade (vínculos quanto à destinação, modificação etc.), porquanto neste caso a Administração possuiria poderes sobre tais bens, tratando-se, no caso, daquilo que alguns doutrinadores afirmam ser "bens de propriedade privada que pertencem à pública", conceito este que teria sido utilizado inicialmente para as obras de arte. (FIORILLO; FERREIRA; pp. 253-254).
\end{abstract}

A propriedade foi paulatinamente perdendo sua concepção absoluta e passou a ser entendida como realização das pretensões e valores existentes na Constituição, submetida ao cumprimento da função social.

O direito reconhece, tradicionalmente, duas categorias de intervenção estatal na propriedade privada: a) restritiva, em que o "Estado impõe restrições e condicionamentos ao uso da propriedade, sem, no entanto, retirá-la de seu dono"; e b) supressiva, em que "o Estado transfere coercitivamente para si a propriedade de terceiro, em virtude de algum interesse público previsto em lei. O efeito dessa "forma interventiva é a própria supressão da propriedade das mãos de seu antigo titular" (CARVALHO FILHO, 2009, p. 740).

A intervenção estatal, em sentido amplo, pode ser compreendida como "todo ato do poder público que, fundado em lei, compulsoriamente, retira ou restringe direitos dominiais privados." (MEIRELLES, 2012, P. 676).

A propriedade, na concepção inaugurada pela Constituição Cidadã, sujeita-se às expectativas sociais, devendo seu uso alinhar-se às políticas estabelecidas pelo governo para estabilizar o convívio social.

A desapropriação pode perfeitamente servir de instrumento a essa relativização do direito de propriedade. Numa concepção tradicional, a desapropriação é o procedimento através do qual o poder público, fundado em necessidade pública, utilidade pública ou interesse social, compulsoriamente despoja alguém de um bem certo, usualmente adquirindo-o para si, em caráter originário, mediante indenização prévia, justa e pagável em dinheiro. Excepcionalmente, em relação a certos imóveis 
urbanos ou rurais, por estarem em desacordo com a função social legalmente caracterizada para eles, a indenização se fará em títulos da dívida pública, resgatáveis em parcelas anuais e sucessivas, preservado seu valor real. (MELLO, 2012, p. 881, 882).

Nesse sentido, todo bem móvel ou imóvel, público ou privado, corpóreo ou incorpóreo, pode ser objeto de desapropriação, incluindo-se até mesmo os direitos em geral, com exceção aos personalíssimos.

A CF/88 determina que somente a União possui competência para legislar sobre 0 assunto (art. 22, II, CF), atribuindo a competência aos demais entes capazes de declararem a utilidade pública ou o interesse social de um bem para fins de expropriação e os entes responsáveis pela efetiva desapropriação do bem, ou seja, por praticar os atos concretos para realizá-la.

No caso do processo judicial em análise, o ente político responsável pela desapropriação por utilidade pública do quadro "Miséria e Caridade" foi o Estado de Sergipe.

Os pressupostos que autorizam a desapropriação são: a necessidade pública, a utilidade pública ou o interesse social. Esses pressupostos se encontram previstos no artigo 5ํㅜㄹ inciso XXIV da Constituição Federal. Também deve ser considerada como requisito a necessidade do pagamento de justa indenização, nos termos contidos em lei.

O primeiro pressuposto deve ser entendido como aquela ocasião em que surge um problema inadiável e premente, para o qual a solução indispensável seria incorporar ao domínio público o bem do particular.

Já o segundo, concernente a utilidade pública, pode ser verificado quando a utilização da propriedade for considerada conveniente e vantajosa ao interesse público, não constituindo um imperativo irremovível. Exemplos de tais situações são a segurança nacional, a necessidade de obras de higiene, construção de casas de saúde, conservação ou exploração de serviços públicos, conservação e melhoramento de vias e logradouros públicos e proteção do patrimônio cultural, conforme prescreve o art. 5ำ, I, do Decreto ํ․ 3.365/19417.

7 Dispõe sobre desapropriações por utilidade pública. Art. 5o do Decreto-Lei o․ 3.365/1941: Consideram-se casos de utilidade pública: a) a segurança nacional; b) a defesa do Estado; c) o socorro 
Quanto ao interesse social, este se verifica quando a Administração estiver diante de interesses que atinjam as camadas mais pobres da população, sendo necessária a promoção da melhoria nas condições de vida, a redução de desigualdades, bem como ao melhoramento na distribuição de renda e riquezas. Alguns exemplos de desapropriação fundada no interesse social são a construção de casas populares e o aproveitamento de bens imóveis rurais ou urbanos improdutivos.

O estudo de caso evidenciou a real e concreta efetividade social que o instituto da desapropriação pode proporcionar ao patrimônio cultural estatal, num cenário de entrechoques de interesses, em que a propriedade privada é tradicionalmente protegida.

Dessa forma, partindo de um caso pontual verificado no Estado de Sergipe, pôde-se perceber que a desapropriação, enquanto forma de intervenção do Estado na propriedade pode, sim, servir de instituto hábil para resguardar o patrimônio cultural brasileiro, sendo um mecanismo apto a efetivar o comando constitucional referente à proteção dos bens culturais.

\section{CONCLUSÃO}

É certo que há muito o que aprimorar e aprofundar na construção da memória e da identidade nacional, e o direito, enquanto ciência social que tem por objetivo

público em caso de calamidade; d) a salubridade pública; e) a criação e melhoramento de centros de população, seu abastecimento regular de meios de subsistência; f) o aproveitamento industrial das minas e das jazidas minerais, das águas e da energia hidráulica; g) a assistência pública, as obras de higiene e decoração, casas de saúde, clínicas, estações de clima e fontes medicinais; h) a exploração ou a conservação dos serviços públicos; i) a abertura, conservação e melhoramento de vias ou logradouros públicos; a execução de planos de urbanização; o parcelamento do solo, com ou sem edificação, para sua melhor utilização econômica, higiênica ou estética; a construção ou ampliação de distritos industriais; j) o funcionamento dos meios de transporte coletivo; k) a preservação e conservação dos monumentos históricos e artísticos, isolados ou integrados em conjuntos urbanos ou rurais, bem como as medidas necessárias a manter-lhes e realçar-lhes os aspectos mais valiosos ou característicos e, ainda, a proteção de paisagens e locais particularmente dotados pela natureza; I) a preservação e a conservação adequada de arquivos, documentos e outros bens móveis de valor histórico ou artístico; m) a construção de edifícios públicos, monumentos comemorativos e cemitérios; n) a criação de estádios, aeródromos ou campos de pouso para aeronaves; o) a reedição ou divulgação de obra ou invento de natureza científica, artística ou literária; $p)$ os demais casos previstos por leis especiais. (BRASIL, 1941). 
disciplinar e regular a vida em sociedade, apresenta papel fundamental na eficácia da preservação do passado.

Nesta linha, a Constituição Federal de 1988 estabeleceu uma extensa previsão normativa quanto aos direitos culturais e encarregou-se de definir o conteúdo legal do termo cultura, em conceito amplo, de caráter universalista, que abrange tanto bens materiais, como bens imateriais, sob a figura do "patrimônio cultural brasileiro". Prevê o pleno exercício dos direitos culturais - liberdade de criação, difusão, uso e gozo -, o acesso às fontes de cultura, o incentivo e o fomento para a geração de valores e bens culturais, a fim de se atingir uma democracia cultural.

Mesmo num Estado onde a propriedade privada é extremamente resguardada, tal direito é mitigado em apoio aos interesses coletivos através das formas legítimas de intervenção na propriedade, como o tombamento e a desapropriação.

Referidas formas de intervenção são importantes, cada uma à sua maneira, para resguardar-se o patrimônio cultural nacional, mesmo que, no caso da desapropriação, tenha que se remover o bem do patrimônio de seu titular, transferindo-o ao Estado.

Ficou evidenciada essa forma de proteção estatal ao patrimônio cultural com a análise do processo judicial de desapropriação do quadro "Miséria e Caridade" do pintor sergipano Horário Hora.

Referida obra, pintada em 1884, foi tombada pelo Estado de Sergipe no ano 2000. A despeito do tombamento, encontrava-se em estado precário de conservação nas mãos de seu proprietário, tendo sido, inclusive, penhorada nos autos de um processo trabalhista.

Compreender a propriedade e suas múltiplas possibilidades de restrição é de suma importância para a salvaguarda do patrimônio cultural brasileiro. A desapropriação - intervenção supressiva da propriedade - foi de extrema relevância para a preservação do quadro "Miséria e Caridade" do pintor sergipano Horácio Hora, conforme demonstrado no estudo do processo judicial apresentado neste artigo.

O quadro "Miséria e Caridade", representante do Romantismo brasileiro, alcançou status de patrimônio cultural do povo sergipano, encontrando-se exposto 
permanentemente no Museu Palácio Olímpio Campos, situado na cidade de Aracaju/SE, podendo ser apreciado por todas as pessoas que visitarem esse espaço.

Sem a interferência estatal, a obra de arte poderia ter se deteriorado totalmente, visto que no momento em que houve a desapropriação o quadro se encontrava em precário estado de conservação, penhorado num processo trabalhista em que o Hospital Amparo de Maria, proprietário da obra de arte, figurava como reclamado.

Partindo dessa perspectiva e diante do objeto de estudo deste artigo - a análise do processo judicial de desapropriação do quadro "Miséria e Caridade" percebe-se a relevância da desapropriação no ordenamento jurídico brasileiro como um instrumento apto e eficaz à promoção da salvaguarda do patrimônio cultural brasileiro.

A cultura nacional está presente em um rol extenso de valores, princípios e regras constitucionais, formando o que vem a ser chamado de "ordenação constitucional da cultura", com caráter de direito fundamental pela Constituição Federal de 1988, em que os bens culturais devem ser protegidos, garantidos e fomentados pelo Estado. A análise do processo judicial de desapropriação do quadro "Miséria e Caridade" proporcionou, a partir do raciocínio indutivo, inferir a relevância desse instituto jurídico de intervenção do Estado na propriedade para a perpetuação e manutenção do patrimônio cultural brasileiro.

\section{REFERÊNCIAS}

BRASIL. Constituição da República dos Estados Unidos do Brasil (1934). Disponível em: http://www.planalto.gov.br/ccivil_03/Constituicao/Constituicao34.htm. Acesso em: 06 mar. 2019.

Decreto-lei no 25, de 30 de novembro de 1937. Disponível em: http://www.planalto.gov.br/CCiVil 03/Decreto-Lei/Del0025.htm. Acesso em: 06 mar. 2019.

Decreto-Lei no 3.365, de 21 de junho de 1941. Disponível em: http://www.planalto.gov.br/ccivil 03/Decreto-Lei/Del3365.htm. Acesso em 06 mar. 2019. 
. Supremo Tribunal Federal. 865 - Compatibilidade da garantia da justa e prévia indenização em dinheiro (CF/88, art. 5, XXIV) com o regime de precatórios (CF/88, art. 100). Relator: MIN. ROBERTO BARROSO, Leading Case: RE 922144. 2015. Disponível em: http://www.stf.jus.br/portal/processo/verProcessoDetalhe.asp?incidente=4864567.

Acesso em: 14.mar.2019.

BONAVIDES, Paulo. Curso de Direito Constitucional. 25 $5^{\mathrm{a}}$ ed. São Paulo: Malheiros, 2010.

CAMPELLO, Lívia Gaigher Bósio; COSTA, Welington Oliveira de Souza. Cultura e Multiculturalismo: Identidade LGBT, Transexuais e Questões de Gênero. Revista Jurídica (UNICURITIBA). vol. 01, n. 46, Curitiba, 2017. pp. 146-163.

CARVALHO FILHO, José dos Santos. Manual de direito administrativo. 21. ed. Rio de Janeiro: Lumen Juris, 2009, p.740.

CUNHA FILHO, Francisco Humberto. Cultura e Democracia na Constituição Federal de 1988: representação de interesses e sua aplicação ao Programa Nacional de Apoio à Cultura. Rio de Janeiro: Letra Legal, 2004.

DANTAS, Fabiana Santos. O Instituto do Patrimônio Histórico e Artístico Nacional (IPHAN): um estudo de caso em direito administrativo. RDA - Revista de Direito Administrativo, Rio de Janeiro, v. 264, p. 223-243, set/dez. 2013. Disponível em http://bibliotecadigital.fgv.br/ojs/index.php/rda/article/view/14082/12951. Acesso em: 26 mar. 2019.

FARIAS, Cristiano Chaves de. ROSENVALD, Nelson. Direito Civil, teoria geral. Rio Janeiro: Lumen Juris, 2011.

FIORILLO, Celso Antônio Pacheco. FERREIRA, Renata Marques. Revista Jurídica (UNICURITIBA). vol. 03, $\mathrm{n}^{\circ}$. 48, Curitiba, 2017. pp. 243-270.

FIUZA, C. Direito Civil: Curso Completo. 14. ed. Belo Horizonte: Del Rey, 2010.

FUNARI, Pedro Paulo Abreu; PELEGRINI, Sandra C. A. Patrimônio Histórico e Cultural. Rio de Janeiro: Zahar, 2006. p. 36. (Coleção Passo a Passo).

G1. 'Miséria e Caridade' de Horácio Hora é considerada a obra de maior valor no estado. 2017. Disponível em: http://g1.globo.com/se/sergipe/bom-diasergipe/videos/v/miseria-e-caridade-de-horacio-hora-e-considerada-a-obra-de-maiorvalor-no-estado/5789927/. Acesso em 14mar. 2019.

HARADA, k. Desapropriação. Doutrina e Prática. 11. ed. São Paulo: Atlas, 2015.

MEIRELLES, Hely Lopes. Direito Administrativo brasileiro. 39a Ed. São Paulo: Malheiros, 2012. 
MELLO, Celso Antônio Bandeira de. Curso de Direito Administrativo. 30 ed. - São Paulo: Malheiros Editores, 2012.

MOURA, Ângela Acosta Giovanini de. A relativização do direito de propriedade face à proteção do meio ambiente: uma análise à luz dos direitos fundamentais. Diké: Revista do Mestrado em Direito da UFS, Aracaju, vol. 03 n 01, jan/jul/2014, p.69 a 82, Agosto/2014. Disponível em file:///C:/Users/Ari/Downloads/2875-8029-1PB\%20(1).pdf. Acesso em: 26 mar. 2019.

NASCIMENTO, Maíra Helena Cerqueira; PASSOS, Lucas Santos. Aracaju/SE: entre o pretérito e o porvir - bens tombados em Aracaju. Disponível em: http://culturadigital.br/politicaculturalcasaderuibarbosa/files/2012/09/Lucas-Santos-

Passos-et-alii.pdf. Acesso em: 14 mar. 2019.

RANIERI, Nina Beatriz Stocco. A Convenção sobre a Proteção e a Promoção da Diversidade Cultural e a Constituição brasileira. Revista da Faculdade de Direito da Universidade de São Paulo. v. 103 p. 303 - 321 jan./dez. 2008. Disponível em https://www.revistas.usp.br/ffdusp/article/view/67807/70415. Acesso em: 26 mar. 2019.

SALLES, Maria Beatriz Correa. A Lei da Cultura e a Cultura da Lei. 2013. Dissertação (Mestrado). Faculdade de Direito, Universidade São Paulo, São Paulo, 2014.

SILVA, José Afonso. Ordenação Constitucional da Cultura. São Paulo: Malheiros, 2001.

VARELLA, Guilherme Rosa. Plano Nacional de Cultura: elaboração, desenvolvimento e condições de eficácia. 2013. Dissertação (Mestrado). Faculdade de Direito, Universidade São Paulo, São Paulo, 2013.

VELOSO, Mariza Motta Santos. Nasce a Academia SPHAN. Revista do Patrimônio Histórico e Artístico Nacional, Rio de Janeiro, n. 24, p. 78, 1996.

ZANDONADE, Adriana. O Tombamento à luz da Constituição Federal de 1988. São Paulo: Malheiros Editores, 2012. 